LA MÚSICA EN TERRITORIO ESCOLAR PRIMARIO: REFLEXIONES SOBRE LAS TRADICIONES PEDAGÓGICAS Y EL DEBATE SOBRE LA INTENCIÓN DE LA ESCUELA POR LA MÚSICA Y LA INTENCIÓN DE LA MÚSICA POR LA ESCUELA. PÁGINAS 63-82 EN REVISTA DE la Escuela de Ciencias de la Educación, AÑo 11, número 10, enero a diciembre de 2015. ISSN 1851-6297. ISSN EN LINEA 2362-3349.

\title{
LA MÚSICA EN TERRITORIO ESCOLAR PRIMARIO: REFLEXIONES SOBRE LAS TRADICIONES PEDAGÓGICAS Y EL DEBATE SOBRE LA INTENCIÓN DE LA ESCUELA POR LA MÚSICA Y LA INTENCIÓN DE LA MÚSICA POR LA ESCUELA.
}

\author{
Por Carlos Peralta* \\ Universidad Nacional de Rosario, Argentina. \\ cperalta2005@yahoo.com.ar
}

Recibido: 30/06/2014 Aceptado: 15/09/2014

\section{Resumen}

El artículo presenta una problematización pedagógica en el territorio de la escuela primaria de educación común (en Provincia de Santa Fe-Argentina) en la cual se destaca una tensión curricular compleja que discute sobre la música y un sentido pedagógico que la piensa parte de la cultura y el proyecto escolar. Tal cuestión propone un estudio crítico sobre la intención de la escuela por la música pero además, una intención de la música por la escuela, considerando que estas intenciones no coinciden. Asimismo uno de los focos está puesto en la posición del docente de música en tanto y por un lado actor del escenario/territorio escolar, por otro formado desde, y centinela de, las ambiciones disciplinares del campo específico de la música.

\section{Palabras clave:}

Educación musical - Campo curricular - Formación docente - Desempeño docente - Escuela primaria.

\section{Abstract}

This article tries a study of a pedagogical issue from critical approach in the field of the formal education in primary school (Santa Fe Province- Argentina) in which a complex curricular tension is highlighted. This tension discusses about music and

* Miembro Investigador Proyecto "Configuraciones en los territorios artísticos contemporáneos. Prácticas artísticas y educación", Escuela de Posgrado, Facultad de Humanidades y Artes, (UNR). Lic. en Calidad de la Gestión Educativa (Univ. Del Salvador). Maestrando en Educación Artística -en instancia de tesis- (UNR). 
Revista de la Escuela de Ciencias de la Educación, año 11, número 10, enero a diciembre de 2015. PÁginas 63-82. ISSN 1851-6297. ISSN EN LINEA 2362-3349. LA MÚSICA EN TERRITORIO ESCOLAR PRIMARIO: REFLEXIONES SOBRE LAS TRADICIONES PEDAGÓGICAS Y EL DEBATE SOBRE LA INTENCIÓN DE LA ESCUELA POR LA MÚSICA Y LA INTENCIÓN DE LA MÚSICA por la escuela. Carlos Peralta

about a pedagogical way for conceives this music as part of the culture and the school project. This study proposes a critical approach about two questions: What's the school intention for the music? What's the music intention in the school? We know that both intentions are different.

We then asked for the teacher's perspective of music when he must synthesize both intentions in their own praxis. We refer to music as a formal discipline trying to overcome contextual ecological constraints, and music as contextual construction trying framed necessarily to school territory.

\section{Key words:}

Music education - Curricular field - Teacher training - Teacher praxis - Basic education school.

\section{Introducción}

En este trabajo intentamos una aproximación reflexiva hacia las tradiciones pedagógicas que posicionaron a la música y la educación musical en la escena de la educación primaria común. Todo aquello "entendible por música" en este ámbito educativo tuvo una presencia y sostenimiento curricular a lo largo del siglo XX (y actualmente) que podría presumirse indiscutible, pero asimismo por esta falta de discusión, se le eximió de examen e interpelación, quedando la música relegada de la agenda de prioridades pedagógicas, y considerablemente irrelevante a los objetivos educativos. Sobre esto bastaría hacer lectura de los textos de Terigi (1999; 2007) acerca del lugar que las artes (la música entre ellas) ocupan en el currículum escolar. Además, que las actividades musicales (y los aprendizajes correspondientes) no sean un factor a tener en cuenta para las evaluaciones de calidad educativa, es objeto de análisis y reflexión. Por si fuera poco, un vistazo a la infraestructura escolar de educación primaria permitiría constatar pocos indicadores de intenciones evidentes hacia las actividades musicales. Pero además, desde otra perspectiva, encontramos en dichas organizaciones educativas una singular forma de pensar y construir un mundo de la música que no se condice precisamente con el lenguaje musical disciplinar formalizado por la tradición musical. Es fundamentalmente sobre esto último que profundizamos valiéndonos además de un trabajo de investigación (1) proyectado sobre la formación del músico-docente y las relaciones que éste establece, o que se desprenden de su potencial desempeño en escuelas primarias comunes. En la cotidianeidad (2) escolar, el docente de música es la figura donde confluyen o se hibridan varios campos simbólicos y/o territorios culturales. Esto suscita tensiones pedagógicas, las cuales serán profundizadas en adelante.

La situación de tensión que más interesa aquí se asienta sobre un escenario que aún no asume responder ante un interés de la escuela por la música 
Revista de la Escuela de Ciencias de la Edducación, año 11, número 10, enero a diciembre de 2015. PÁginas 63-82. ISSN 1851-6297. ISSN EN LINEA 2362-3349. LA MÚSICA EN TERRITORIO ESCOLAR PRIMARIO: REFLEXIONES SOBRE LAS TRADICIONES PEDAGÓGICAS Y EL DEBATE SOBRE LA INTENCIÓN DE LA ESCUELA POR LA MÚSICA Y LA INTENCIÓN DE LA MÚSICA por la escuela. Carlos Peralta

que no es el mismo que el de la música por la escuela. Al respecto indagamos qué tipo de escuela se interesa por qué tipo de música y viceversa. Y, sobre uno de los protagonistas principales de esta escena escolar, observamos que el docente de música se forma en instituciones (3) que piensan la música de cierta manera, y luego se desempeña en ámbitos educativos que la piensan distinto. Con esto último aludimos a quienes egresan de instituciones de formación musical y luego se desempeñan en instituciones escolares de nivel/ modalidad primario/común.

Distinguir un interés de la escuela por la música es referirse a casi un siglo de música componiendo el currículum escolar; es decir, se ha diseñado un currículum que previó intencionalmente proyectar actividades en relación con el quehacer musical formal, para su proyecto pedagógico escolar.

Advertir un interés de la música por la escuela es analizar lo que subyace fundamentalmente a través de la formación docente (4). Quienes egresan de las instituciones de formación musical para desempeñarse como docentes de música lo hacen con una férrea formación caracterizada, signada y sellada por el encuadre dado a la música desde las categorías modernas: lo entendible por música corresponde a un campo disciplinar, y debe salvaguardar los aspectos formales canonizados (5), más allá del contexto por el cual circule. Así ha de ser formalmente presentada en territorio escolar por intermedio del docente (6).

\section{Música y escuela}

Al relacionar música y escuela según intereses de una para con la otra y viceversa, es preciso intentar conceptualizar ambos términos. Valga el esfuerzo sobre todo por entender que tanto escuela como música son términos que por su amplitud conceptual y su frecuente uso de sentido común, se perderían en un mar de significados de no acotar un marco inteligible. Entonces en esta relación se entiende por música a las prácticas (7) organizadas y regidas por un campo disciplinar que comprende y entiende sobre un paradigma moderno, reglas positivistas de orden, racionalidad, verdad, universalidad, que asientan y promulgan criterios ideológicos, estéticos y metodológicos para esas prácticas musicales, lo cual les atribuye validez y así las legitiman formalmente. Las instituciones de formación musical (como también otras instituciones del acervo cultural y social) tomarán este referente del mundo de la música como eje de sus intenciones/proyecciones artístico-educativas. Sus prácticas, diseños curriculares y objetivos institucionales girarán sobre él. Básicamente por este motivo, a los fines de este trabajo hacemos referencia a esta manera de entender la música, y no a otra (8).

Relacionada en este trabajo con la música, la escuela como institución cuya dependencia organizativa es regida y regulada por el Estado y por actuaciones de políticas centrales, es entendida aquí como un territorio donde se 
Revista de la Escuela de Ciencias de la Educación, año 11, número 10, enero a diciembre de 2015. PÁginas 63-82. ISSN 1851-6297. ISSN EN LINEA 2362-3349. LA MÚSICA EN TERRITORIO ESCOLAR PRIMARIO: REFLEXIONES SOBRE LAS TRADICIONES PEDAGÓGICAS Y EL DEBATE SOBRE LA INTENCIÓN DE LA ESCUELA POR LA MÚSICA Y LA INTENCIÓN DE LA MÚSICA por la escuela. Carlos Peralta

formalizan las prácticas pedagógicas en pos de un proyecto educativo sociocultural. Sobre lo cual hay que entender una dinámica escolar que orienta estas prácticas desde un sentido prescripto o apriorístico, y que además y al mismo tiempo es permeable a aquellas (prácticas) que emergen de la misma cultura escolar (9), del propio devenir cotidiano, de sus actores y de las relaciones y construcciones simbólicas y concretas que éstos producen.

En el sentido que vamos a seguir, las prácticas pedagógicas escolares tanto ponen en juego significados y perspectivas (10) desde una formalidad dada por una intencionalidad oficial, por ejemplo el diseño curricular, como también los que emergen de manera informal cuya intencionalidad más tiene que ver con construcciones culturales contextuales, por ejemplo un currículum oculto (11). En lo que concierne a la educación musical el currículum oculto tiene una sobredimensionada presencia al punto tal de atenuar la figura del currículum formal/prescripto o disputarle legitimidad. Esto se desarrollará más adelante.

En sí, y para el caso, la escuela pudiera ser un territorio que condensa todo aquello que generalmente alude a la educación formal; una institución/ organización que cristaliza las aspiraciones (socialmente legítimas) pedagógicas-educativas básicas y transversales a un devenir socio-cultural; un medio ambiente que construye una cultura que intenta dirigirse a (sino consolidar) un proyecto nacional; un territorio donde confluyen tradicionalmente masas diversas y diversificadas de sujetos y del cual surgen prometedores modelos ciudadanos; el espacio donde se debaten expectativas apriorísticas con construcciones culturales a la orden del día. Ahora, y pudiendo además considerar un sinnúmero más de conceptualizaciones sobre la escuela, bien vale observar entonces un conjunto de significados a arbitrarse pertinentes y relevantes para circular por allí y los modos en que esto pudiera ocurrir. La educación musical y con ella los significados relativos a la música, tempranamente (12) conformaron ese capital cultural distinguido e inobjetable para incluirse en la propuesta educativa escolar.

Pero si bien en un principio se ha intentado imitar (y trasplantar) el modelo europeo donde las actividades musicales formales eran emblema distintivo de elite y de suficiencia educativa, luego, la educación musical en las escuelas abiertas a las masas y con esto a la popularización de su aspecto formal quedaría comprometida a re-significar su expectativa, su territorialización, su presencia curricular. Entonces, a partir de allí, la música es también una construcción cultural pero no a tono de aquella antes definida como herencia de la teoría y práctica clásica europea que nos fuera tradicional. La pregunta obligada entonces es: qué tipo de música la escuela construye y con qué interés. Una primera contradicción y/o tensión surge al observar que el diseño curricular (13) para educación musical viene apoyando o sosteniendo tradicionalmente las propiedades del campo disciplinar de la música. Sin embargo esta direccionalidad curricular viene siendo débil e inconsistente en medio del ruido de la 
Revista de la Escuela de Ciencias de la Edducación, año 11, número 10, enero a diciembre de 2015. PÁginas 63-82. ISSN 1851-6297. ISSN EN LÍNEA 2362-3349. LA MÚSICA EN TERRITORIO ESCOLAR PRIMARIO: REFLEXIONES SOBRE LAS TRADICIONES PEDAGÓGICAS Y EL DEBATE SOBRE LA INTENCIÓN DE LA ESCUELA POR LA MÚSICA Y LA INTENCIÓN DE LA MÚSICA por la escuela. Carlos Peralta

cultura escolar. Generalmente la cultura escolar refleja distinto modo de pensar el mundo de la música, o podría decirse; distinto interés por la música, o interés en un mundo musical distinto.

Hemos desarrollado hasta aquí un recorte conceptual útil para entender los términos con los cuales nos referimos a la música como categoría disciplinar tradicional de herencia europea interpelada luego y a partir de pensarla como construcción cultural contextual. Asimismo, hemos hecho referencia a la escuela como espacio relacional entre significados y prácticas, entre expectativas proyectadas y experiencias emergentes, y cuyas construcciones culturales resultan de las interacciones de sus actores.

Se han entablado algunas relaciones entre estos términos. Esto ha puesto luz sobre posibles discusiones y potenciales debates al interior del contexto (14) escolar para construir allí un mundo de la música según los intereses de turno. De tal manera que considerando las formulaciones de Alicia De Alba (1991) al respecto, estas discusiones son discusiones curriculares o pueden darse al interior de un campo curricular. Sostenemos apropiada la definición de currículum (15) que hace esta autora para entender las situaciones que de este término se desprenden y que son centrales a este trabajo.

\section{Perspectiva curricular: relaciones entre el escenario escolar-docente de música}

Consideramos que este campo del currículum para una música con intenciones pedagógicas o para una propuesta educativa interesada en la música, involucra dos núcleos de construcciones curriculares: las que estructuran un diseño curricular formal o prescripto, y las que constituyen un currículum oculto o donde emergen situaciones curriculares venidas de realidades cotidianas aún informales o excluidas en la documentación curricular formal.

Advertimos que ambos núcleos más bregan por mal-calificarse mutuamente y a la vez por ratificarse a sí mismos legítimos y con cierto celo de autenticidad, que por amalgamarse o confluir hacia un formato/discurso pedagógico musical sostenedor de las prácticas. Aún así sospechamos que los procesos de hibridación entre ambos núcleos son inexorables.

El primer núcleo curricular procura unos fundamentos pedagógicos orientados a promover la conservación de las propiedades puras y canonizadas de la música como disciplina moderna. De esta forma recaba en las instituciones del academicismo musical y aquellas conservadoras de tal canon, los supuestos teórico-prácticos y formales desde donde legitimar esta forma de pensar la música. Por lo mismo intenta evitar el roce con otras formas de pensarla.

El segundo núcleo persigue una orientación pedagógica que promueve la inclusión y circulación en territorio escolar de significados y ergo prácticas en torno a la música, que no provienen del academicismo musical tradicional 
Revista de la Escuela de Ciencias de la Educación, año 11, número 10, enero a diciembre de 2015. PÁginas 63-82. ISSN 1851-6297. ISSN EN LINEA 2362-3349. LA MÚSICA EN TERRITORIO ESCOLAR PRIMARIO: REFLEXIONES SOBRE LAS TRADICIONES PEDAGÓGICAS Y EL DEBATE SOBRE LA INTENCIÓN DE LA ESCUELA POR LA MÚSICA Y LA INTENCIÓN DE LA MÚSICA por la escuela. Carlos Peralta

y clásico, sino más de afluentes culturales de tinte sociológicos (16). Es decir, surgen de la manera en que la música en sus variadas formas, acepciones y motivaciones impacta sobre, o anida en los sectores sociales, y de cómo la escuela es permeable a esta cuestión, la refleja, y/o la reproduce o construye sobre.

Por ejemplo, cuando las prácticas musicales procuran que los alumnos canten afinados o que intelectualicen un pasaje de figuración rítmica según la normativa de lectoescritura musical convencional y a su vez se hace necesario llegar a estos objetivos, tales prácticas pueden considerarse sostenidas por construcciones curriculares del primer núcleo. Y un segundo núcleo de construcciones curriculares podría asistir el planteo de prácticas en torno a la música del tipo a cuando por ejemplo el docente de música es promotor de bailes festivos improvisados, o cuando comparte ciertas solicitudes escolares como amenizar con música números artísticos para los actos y efemérides escolares, o cuando la responsabilidad por enseñar las canciones patrias e himnos recae en sus espaldas, o cuando se proyectan en las prácticas las opiniones personales de los distintos actores escolares y de la cultura escolar misma (directivos, otros docentes, alumnos, personal no docente, padres, etc.) acerca de qué y cómo debe entenderse sobre música, o cuando se asume lo referido a la educación musical como subsidiario de todo aquello a considerase prioridad educativa escolar.

En el sentido en que ambos núcleos pugnan por autoafirmarse como legítimos para llevar a escena un mundo de la música de contexto escolar, se nutre un campo del currículum candente y movilizado de discusiones y negociaciones. Podríamos reflexionar sobre esta mecánica desde aquello que Basil Bernstein (1998; 2001) llamara dispositivo pedagógico y en términos de una clasificación fuerte (de significados formales) y un enmarcamiento demasiado débil sobre los modos en que estos significados se presentan y circulan. El campo del currículum (y aquello que allí se cuece), en tanto dispositivo pedagógico, al fin de cuentas resume o traduce hacia las prácticas escolares los criterios que se asumen como válidos o con validez formal para pedagogizar y escolarizar ciertos (y sólo ciertos) modelos atribuibles al mundo de la música.

En el devenir de este campo curricular y presentado así como lo hemos intentado, se piensan y construyen los formatos que dan entidad a la música en la escuela primaria.

Entonces hemos procurado describir y comprender sobre dos núcleos como agentes protagonistas del campo curricular, prestos a discutir qué se entiende por música y cómo, y qué de esto es relevante de llevar a las prácticas escolares. Uno (núcleo) interesado en que la escuela reproduzca y desarrolle la normativa musical clásica como campo disciplinar. El otro, con la intención de que las prácticas musicales sean teñidas del acontecer musical emergente del contexto sociocultural próximo. A su vez el docente de música interviene 
Revista de la Escuela de Ciencias de la Edducación, año 11, número 10, enero a diciembre de 2015. PÁginas 63-82. ISSN 1851-6297. ISSN EN LINEA 2362-3349. LA MÚSICA EN TERRITORIO ESCOLAR PRIMARIO: REFLEXIONES SOBRE LAS TRADICIONES PEDAGÓGICAS Y EL DEBATE SOBRE LA INTENCIÓN DE LA ESCUELA POR LA MÚSICA Y LA INTENCIÓN DE LA MÚSICA por la escuela. Carlos Peralta

oscilando en tal discusión curricular, posicionado a veces en uno de esos núcleos desde su formación musical institucional, o en el otro, desde la mera experiencia escolar contextual. Al respecto vemos conveniente ahora intentar profundizar la construcción de un mundo musical en este contexto, sobre dos factores que se relacionan bajo tensión:

1-La música como disciplina no es un eje en torno al cual gira el proyecto pedagógico de las instituciones escolares de educación primaria, tal como sí lo hace en una academia, conservatorio o escuela de música. El mundo escolar de la música (o el mundo musical de la escuela) es una construcción de la cultura escolar institucional; es fruto del contexto. La discusión curricular que arbitra qué es música, cómo se piensa su substancia y hasta dónde alcanza conceptualmente se da al interior de la institución. Ahora bien, los docentes de música que actúan y se desempeñan en este territorio no se han formado (institucionalmente) en este modo de pensar y construir el mundo de la música.

2-Los docentes de educación musical se forman en instituciones que giran en torno a la música desde una perspectiva disciplinar. Es decir; instituciones que piensan y construyen el mundo de la música desde los cánones consagrados por los formatos que Argentina heredó de la Modernidad europea, cuestión que ya se ha dicho antes. Aquí, quien se jacte de producir música o entender sobre, debe hacerlo dentro de aquello que es válido según parámetros estéticos, lingüísticos y metodológicos determinados, que aplican sobre el perfil constitutivo de las instituciones (sean instituciones tradicionales de la cultura, como de la educación). En cierto sentido, los docentes de educación musical son substancia de lo aquí expuesto.

Por lo anterior, si los docentes formados en instituciones que piensan la música de cierta manera, se desempeñan en ámbitos educativos que la piensan distinto, surge aquí una tensión pedagógica-curricular para la enseñanza de música, cuestión que se viene elucubrando.

La formación docente es uno de los factores a considerar ineludibles para revisar cómo se ha pensado y se piensa a la música y la educación musical en ámbitos de educación masiva, obligatoria, común y básica; donde lo artístico lejos de ser un eje institucional, es uno entre tantos discursos pedagógicos, y rara vez prioritario. En la figura del docente de música se funden variadísimas presunciones para cargar de sentido estético a las producciones musicales escolares. Ella conlleva una potestad para interpretar el currículum prescripto y a la vez sopesar las ambigüedades e informalidades emergentes en torno a la música. Ahora, tanto este docente construye su figura (o su praxis), como le es construida por la cultura y el proyecto escolar. Entonces, ¿es el docente de música un co-constructor de la cultura musical que circula en el contexto escolar en tanto campo pedagógico? ¿Es el docente portavoz y/o centinela al resguardo del campo disciplinar de la música aún despreocupado por su contextualización material e histórica? ¿O, al fin de cuentas es un agente regulador? Es posible 
Revista de la Escuela de Ciencias de la Educación, año 11, número 10, enero a diciembre de 2015. PÁginas 63-82. ISSN 1851-6297. ISSN EN LINEA 2362-3349. LA MÚSICA EN TERRITORIO ESCOLAR PRIMARIO: REFLEXIONES SOBRE LAS TRADICIONES PEDAGÓGICAS Y EL DEBATE SOBRE LA INTENCIÓN DE LA ESCUELA POR LA MÚSICA Y LA INTENCIÓN DE LA MÚSICA por la escuela. Carlos Peralta

que el docente (su forma y función) vaya a la par de los intereses escolares en materia musical y se haya caracterizado de distintas maneras según el devenir histórico. Por lo pronto cabe hacer alusión a este "devenir histórico" que ha venido configurando la figura del docente de música en relación a la música vigente en la escuela a lo largo, al menos, del Siglo XX.

\section{La tradición musical en la escuela, o la música en la escuela tradicional.}

La música en tanto disciplina, y a través de las instituciones de la cultura y algunas educativas que giran en torno a ella, ha aparecido como impronta moderna presentándose formalmente de cierta y sólo de cierta manera ante la sociedad. Esto se traduce en normas y territorios prescriptos desde un encuadre paradigmático. Y de esto mismo se deduce que no todos los sectores sociales han tenido libre acceso, o admisión incondicional para acceder y circular por "este mundo de la música y desde esta perspectiva". Por ejemplo, la música popular argentina ha quedado tradicionalmente excluida (17) (del currículum formal) de estas instituciones de la cultura y la educación, por tanto de las instituciones de formación docente, por tanto de la formación del docente de música. Tradicionalmente la cultura de clase o específicamente la música culta, académica, quedó ligada a ciertos sectores sociales próximos a campos simbólicos "propios de la hegemonía". Pero cuando la escuela se abre a las masas (18) se re-organizan los territorios institucionales de circulación de la música. Entonces la música culta, académica (el discurso oficial sobre música) que paralelamente conservará ciertos territorios de circulación ligados a la cultura, comienza a ser interpelada sobre la perspectiva con la cual tendrá cabida en un ámbito educativo popularizante y masivo como la escuela primaria común, y en el mismo sentido; sobre las maneras de resolver su pertinencia al proyecto educativo. En otras palabras; en qué formato musical se la requerirá y cómo circulará aquí y ahora, y de qué maneras aceptará (negociará) presentarse entonces (19). Por lo pronto y respecto a lo musical, la discusión apunta a debatir si es preciso enriquecer las referencias disciplinares; en algún sentido, propiciar revisiones y regulaciones de mayor frecuencia y calidad entre aspectos de la teoría, la práctica y el contexto. Por otra parte, no ha sido muy empeñosa la tarea de atender sobre el impacto que en los actores escolares la música ha suscitado ni hubo vehemencia para comprender los motivos. Pero pensamos que, por ejemplo, no podemos quedar indiferentes a aquel sector de la comunidad partidario por disminuir espacios a las áreas artísticas en pos de aumentar áreas más importantes: nos referimos a los resultados de aquella encuesta La familia opina (20). Tampoco soslayar las opiniones de egresados de instituciones de formación musical que sostienen como realidades incompatibles o ser músico o ser docente en escuela (21). Quizás al respecto podamos interpretar que si la presencia de la música en la escuela no ha resultado o 
Revista de la Escuela de Ciencias de la Edducación, año 11, número 10, enero a diciembre de 2015. PÁginas 63-82. ISSN 1851-6297. ISSN EN LÍNEA 2362-3349. LA MÚSICA EN TERRITORIO ESCOLAR PRIMARIO: REFLEXIONES SOBRE LAS TRADICIONES PEDAGÓGICAS Y EL DEBATE SOBRE LA INTENCIÓN DE LA ESCUELA POR LA MÚSICA Y LA INTENCIÓN DE LA MÚSICA por la escuela. Carlos Peralta

no se ha valorado debidamente (22) en tanto potencial educativo, es más por desatención que por irrelevancia pedagógica. Esta desatención nunca inocua y sinsentido, posiblemente haya preferido no prestarse a resolver sobre las tensiones del campo del currículum debatido en construir un camino para la praxis (23) musical entre al menos tres argumentos en discusión: la música 1) como emblema conservador del progreso del orden positivista en tanto campo específico de estudio y disciplina, 2) aunque relegada tras la reducción y centralización de la oferta educativa a la enseñanza de saberes mínimos y básicos, 3) y/o encausada a través del ritual folclórico-populista-nacionalista y la apertura a las masas y las culturas populares.

¿Será que de algún modo el desaire del lenguaje musical específico en el ámbito escolar primario se percibe como amenaza a la autonomía del campo musical específico (al cual representaría)? Y en todo caso, ¿la praxis musical en la escuela primaria ultraja las propiedades del campo musical disciplinar, resultando en desdibujadas formas estéticas al límite de sus referencias disciplinares?

O por otro lado; si la escuela de enseñanza primaria común re-contextualiza (24) los campos de manera tal que transforma elementos del campo disciplinar de la música en elementos de un campo pedagógico, y por tanto precisa ya de especialistas en el campo de la pedagogía antes bien que especialistas en el campo de la música, cómo se predispone el o al docente de música para moverse en campos indeterminados desde las rupturas de los paradigmas que tradicionalmente le concibieron.

¿Hasta dónde es posible el sostenimiento modernizador de un orden dado por la tradición que pretendía en rigor la autonomía del campo musical? ¿En qué punto el proyecto escolar moderno para la música oferta y permite una socialización del campo musical dispuesto curricularmente en disciplinas, en un territorio masivo y popular, y que además apunta con mayor esmero las expectativas educativas a otras áreas del conocimiento (saber mínimamente escribir, leer y calcular), donde la música no calificaría entre tales.

¿O será que la música escolarizada es una manera de democratizar la disciplina musical y el fin justifica todo medio? Al respecto García Canclini (2010) expone que los caminos por donde, socioculturalmente, se ha pretendido socializar y/o democratizar el arte (la música incluida) en Latinoamérica no retribuyeron las expectativas allí puestas, y que por ejemplo, artistas y sociólogos suponen que en el caso de las producciones musicales

(...) concebidas teniendo en cuenta la autonomía moderna de las búsquedas formales, hechas para espacios donde esos lenguajes insulares puedan hablar sin interferencias, suelen volverse mudas cuando son vistas en medio del ruido urbano por espectadores que no andaban por la calle ni llevaron sus hijos al parque dispuestos a tener experiencias estéticas (García Canclini, 2010, p.139). 
Revista de la Escuela de Ciencias de la Educación, año 11, número 10, enero a diciembre de 2015. PÁginas 63-82. ISSN 1851-6297. ISSN EN LINEA 2362-3349. LA MÚSICA EN TERRITORIO ESCOLAR PRIMARIO: REFLEXIONES SOBRE LAS TRADICIONES PEDAGÓGICAS Y EL DEBATE SOBRE LA INTENCIÓN DE LA ESCUELA POR LA MÚSICA Y LA INTENCIÓN DE LA MÚSICA por la escuela. Carlos Peralta

Correspondiendo una paráfrasis a lo anterior, la inquietud lleva a preguntarse entonces: en la escuela primaria de educación común, qué actores de la escena escolar cotidiana están predispuestos y cómo a formar parte de las experiencias estéticas que el lenguaje musical formal disciplinar posibilitaría allí. Pero la pregunta dispara otro interrogante más agudo y tal vez inverso: qué tipo/s de lenguaje/s o formato/s musical/es está/n dispuesto/s a suscitar experiencias estéticas en los actores escolares, la cultura y la cotidianeidad escolar allí donde no se sostuvo en el tiempo un espacio destinado a la música en tanto praxis de corte disciplinar, o simplemente no fue pensado para ello. $Y$ por esto último no es fácil esperar que los actores escolares se movilicen hacia el formato musical tradicional disciplinar o se apropien de experiencias estéticas desde éste. Al respecto parecería entonces auspicioso un formato musical, otro, que pueda movilizar a los actores escolares, predisponerlos sensiblemente a experiencias estéticas. Sería prometedora una música que pueda capitalizar toda experiencia musical de los actores, aún informal, contextual o cultural, sin el intento persistente de ceñirla totalitariamente al lenguaje musical disciplinar. No obstante, sin desentenderla radicalmente de éste.

\section{La escuela y la música: de lo macro a lo micro}

Atesorar, en materia musical, las experiencias culturales, subjetivas, sensibles, de todos los actores escolares implica reconocer que diversos mundos musicales pueden no sólo impregnar la cotidianeidad musical de la escuela, sino a la vez contribuir a la construcción de una entidad. Evidentemente la escuela no puede acotarse y encerrarse en lo meramente prescriptivo, normativo y proyectado, sino descubrirse permeable.

La permeabilidad de la organización escolar promueve una traducción constante (formal o informal) de los significados y significantes socioculturales del contexto social (inmediato, mediato y global) en significados pedagógicos. Esto monta un escenario escolar propenso a hacer circular los contenidos y discursos sociales, y tendiente a una reproducción de los mismos (en el caso de sostener las teorías reproductivistas) o bien a una construcción simbólica cuya formalización y legitimidad quedarán dispuestas e instituidas por las fuerzas sociales capaces de imponerse. En materia musical, la cultura escolar un tanto refleja y un tanto produce significados concomitantes a aquellos de la cultura social amplia. No nos ha sorprendido encontrar indicios escolares que consignan a la música a emplazarse en el mismo sitio donde la dispuso la cultura social, y a prestarla a similares consideraciones. En este caso corresponde si no definir, al menos caracterizar la cultura social. Intentamos describirla para comprender qué tipo de discursos vehiculiza la escuela, de dónde vienen y a quiénes pertenecen. Referirse aquí a la cultura social no puede reducirse a explayarse sobre cierto sector, aún sea el hegemónico, aún el de mayor repu- 
Revista de la Escuela de Ciencias de la Edducación, año 11, número 10, enero a diciembre de 2015. PÁginas 63-82. ISSN 1851-6297. ISSN EN LÍNEA 2362-3349. LA MÚSICA EN TERRITORIO ESCOLAR PRIMARIO: REFLEXIONES SOBRE LAS TRADICIONES PEDAGÓGICAS Y EL DEBATE SOBRE LA INTENCIÓN DE LA ESCUELA POR LA MÚSICA Y LA INTENCIÓN DE LA MÚSICA por la escuela. Carlos Peralta

tación y popularidad. Habría que pensar una amplitud abarcativa de todas las probabilidades de cultura social que pudieran caber en la escuela, o sobre las que la escuela pudiera ser competente o bien admitiera interés. A lo largo de la historia, los sectores dirigentes desplegaron cabalmente su menú de opciones del cual elegir y al cual atenerse (por someterse). Definieron las ambivalencias y distinciones entre clases: ricos/pobres, cultos/incultos, urbano/rural, hegemónico/subalterno, dirigentes/dirigidos, guardapolvos blancos para las escuelas masivas (populares)/uniformes singulares para las selectas, familias bien constituidas/familias inapropiadas. Asimismo dispusieron en la escuela un dispositivo de clasificación/control (25) de instrumentación y regulación sobre tal menú. En el caso del proyecto educativo formal y nacional cuyo estandarte es la organización escolar cabe considerar una tradición que consagró una concepción unívoca de cultura a pedagogizar que

(...) ha colaborado en la construcción de un currículum indiscutible, constituido en un fuerte ordenador no sólo de lo que la escuela debe enseñar, sino de lo que un docente debe saber para hacerlo. Es decir, una formación docente limitada, en términos culturales, por el recorte y la certeza de lo que se va a transmitir en la escuela, por la posición de un docente concebido como un eslabón de una cadena jerárquico-burocrática." (Birgin y Serra, p.237) (26).

Las prácticas en relación a la presencia musical en la escuela devinieron tradicionalmente en objeto pedagógico con fines (intenciones políticas a través de formateos estéticos) acordes al proyecto educativo: quizá la configuración de un ciudadano nacional urbano y civilizado en relación con otros pares, idénticos e inmediatos. Consecuentemente, la antesala de estas prácticas arbitraron qué música es bella y apropiada, qué otra es improcedente, cuál representa nuestro orden y progreso como sociedad, y qué mecanismos instituyen el modelo a perpetuar o en lo posible a sostener. Y la escuela posibilita/ó la concreción de estas prácticas y patrones en relación a lo musical, como también otras:

Cuerpos erguidos y en cierta tensión, mobiliario unificado y ascético, vestuario limpio, ámbitos inodoros, presencia de la cultura letrada. Nada de eso es ingenuo: (...) esas opciones condensaron luchas sociales de larga duración que han tenido importantes consecuencias políticas.

Tal vez ése sea uno de los grandes triunfos de la escuela: haber fraguado el futuro mediante la inculcación en grandes masas de población de (formatos y capitales estéticos, y) pautas de comportamiento colectivo basadas en los cánones civilizados de la belleza y la fealdad. La dimensión política de esta operación se torna evidente (Pineau, 2007, p.117). 
Revista de la Escuela de Ciencias de la Educación, año 11, número 10, enero a diciembre de 2015. PÁginas 63-82. ISSN 1851-6297. ISSN EN LINEA 2362-3349. LA MÚSICA EN TERRITORIO ESCOLAR PRIMARIO: REFLEXIONES SOBRE LAS TRADICIONES PEDAGÓGICAS Y EL DEBATE SOBRE LA INTENCIÓN DE LA ESCUELA POR LA MÚSICA Y LA INTENCIÓN DE LA MÚSICA por la escuela. Carlos Peralta

Sobre estas apreciaciones emerge la problemática acerca de las formas, formatos y constructos estéticos que la escuela posibilita (Pineau, 2014) entre las cuales la música se ha prestado a constituir según Terigi (1999) artefactos estéticos.

Aquel formato de educación musical desarrollado en las escuelas, pergeñado por el sistema educativo, donde la música se había fundamentado como disciplina moderna, pronto ha dejado de circular como tal por los espacios escolares, siendo interpelado por las formas socioculturales próximas a la contextualidad escolar. De esta manera ha ido renovando y resignificando el sentido construido en torno a lo musical.

\section{El docente de música, un trayecto teñido de presunciones, experiencias y ambiciones.}

Sobre el último párrafo anterior cabe explayarse en el protagonismo del docente de música, tal vez la figura revestida de relativa autoridad para inferir las producciones musicales escolares en tanto constructos estéticos. De hecho, entonces, saberlo comprometido a regular la oscilación entre la música como obra de arte o como artefacto estético nos exhorta a indagarlo.

Más allá de encontrar en tantos docentes virtudes personales para con su desempeño, aquí pondremos el acento en la formación musical institucional del docente de música, considerando el aspecto sistemático de tal cuestión. Nos inquieta la pregunta de si es posible y/o necesario la constitución de un "perfil del cuerpo docente", sobre todo cuando la historia de las últimas décadas cuenta con un acceso a la docencia de música de un mix de interesados formados tanto en los institutos de formación docente de acreditación formal, en otras instituciones, como por fuera de cualquier institución quedando esto último entre lo informal, lo alternativo y lo personal. Desde tan variadísimas fuentes de formación no resultó en la diversidad, un enriquecimiento de la educación musical a fin de componer un perfil/base de docente de música. Por el contrario, como si cada práctica pedagógica fuera una isla; la suerte de la música en la escuela quedó sellada por el docente que fortuitamente estuviera asignado a cada cargo; a cada puesto; a cada escuela.

Creemos atinado aportar al escrito el planteo de una problemática a través de un trabajo de investigación con una mirada perspicaz sobre algunos criterios pedagógicos en los docentes de música y preferencias de desempeño. Este trabajo llevado a cabo entre 2012 y 2013 fue presentado como avance al XIX Seminario Latinoamericano de Educación Musical, en Montevideo en septiembre de 2013. El problema que plantea indaga sobre las preferencias de desempeño en potenciales docentes (egresados de las instituciones de formación musical) según la formación y ambiciones profesionales. Aquí se ha construido un objeto de estudio referido a la reciprocidad entre la perspectiva 
Revista de la Escuela de Ciencias de la Edducación, año 11, número 10, enero a diciembre de 2015. PÁginas 63-82. ISSN 1851-6297. ISSN EN LINEA 2362-3349. LA MÚSICA EN TERRITORIO ESCOLAR PRIMARIO: REFLEXIONES SOBRE LAS TRADICIONES PEDAGÓGICAS Y EL DEBATE SOBRE LA INTENCIÓN DE LA ESCUELA POR LA MÚSICA Y LA INTENCIÓN DE LA MÚSICA por la escuela. Carlos Peralta

del docente de música para posicionar la música en la institución donde se desempeña, y la música como disciplina a través del canon tradicional de las instituciones de formación. Se han compuesto categorías de análisis: 1) instituciones educativas: en las que la música como disciplina es un eje estructural, y en las cuales la música es una construcción emergente del contexto en cierto punto despreocupada del encuadre disciplinar, 2) el protagonismo del docente de música: solidario al contexto, o centinela al resguardo de las propiedades soberanas de la disciplina musical.

Sobre estos aspectos del trabajo se indaga a una muestras de encuestados (27) sobre los tipos de instituciones que prefieren para desempeñarse como docentes de música, y cuál es la relación conceptual entre músico y docente de música.

La interpretación y el análisis de las respuestas se han encaminado hacia al menos dos tendencias vectores: primero, que la gran mayoría de potenciales docentes de música prefiere de cara a un desempeño docente, instituciones que giran en torno a la música; que están enmarcadas en el canon disciplinar. La escuela primaria común no califica entre tales. Segundo, gran parte de los encuestados asume que tanto músicos como docentes de música son portavoces de este canon, cuyo mérito reside básicamente en atenerse al campo disciplinar de la música.

Para no extendernos demás, encontramos en este proyecto de investigación lucidez para analizar ante todo la preferencia de los encuestados por desempeñarse en instituciones con perspectivas análogas o afines a las de formación. Por ejemplo, quienes egresan del profesorado de música o de la escuela de música de la universidad prefieren desempeñarse como docentes en conservatorios, institutos privados de música, escuelas de música, institutos terciarios de música o artes, y aún en las mismas instituciones donde formaron su especificidad, y otras del tipo.

En seguida nos preguntamos entonces, qué docentes se están desempeñando en la escuela primaria común; qué perfil de docente de música está allí respondiendo a qué principios y a qué fines pedagógicos.

Ahora, si por lo dicho más arriba, el desempeño docente se afianza en perspectivas análogas a las de formación por qué no pensar entonces y también en la posibilidad de perspectivas de formación consonantes y confluentes con las del contexto de desempeño (28). ¿Sería posible trasladar la problematización de la construcción musical en la escuela primaria entre los aspectos universales y los contextuales, a las perspectivas de formación musical, allí al interior de la institución de formación? Y si no trasladarla, al menos comenzarla allí.

Por ahora nos cabe la impresión de que los institutos de formación musical asienten con cierta indiferencia que la escuela primaria común no está del todo interesada en la perspectiva musical que éstos afirman. Sus egresados aterrizan en territorio escolar vehiculizando tal perspectiva y una vez en contexto se 
Revista de la Escuela de Ciencias de la Educación, año 11, número 10, enero a diciembre de 2015. PÁginas 63-82. ISSN 1851-6297. ISSN EN LINEA 2362-3349. LA MÚSICA EN TERRITORIO ESCOLAR PRIMARIO: REFLEXIONES SOBRE LAS TRADICIONES PEDAGÓGICAS Y EL DEBATE SOBRE LA INTENCIÓN DE LA ESCUELA POR LA MÚSICA Y LA INTENCIÓN DE LA MÚSICA por la escuela. Carlos Peralta

hallan en medio de una inminente tensión curricular para la educación musical que precipita su posicionamiento ideológico, epistemológico, paradigmático y metodológico frente al mundo de la música y prácticas consecuentes. Esto los compromete a revisar su presunción docente. Una pregunta quedará pendiente aquí pero es necesario formularla: cómo los docentes logran superar esta dinámica de bienvenida. ¿Serán tal vez virtudes personales?

Ahora si la calidad de la educación musical entonces depende más de virtudes personales (en algunos docentes) que de las aras de la política educativa vigente no hay otra suerte que el azar para firmar la oferta pedagógica musical para cada alumno de cada escuela primaria común.

Pensamos que si en algún momento es pretendida una arquitectura que preste perfil al cuerpo docente hallaremos entre sus compuestos un sustrato estructural donde la música como disciplina está demasiado presente, y también otro donde está casi ausente y que corresponde a aquellos docentes que ingresaron al sistema sin haber pasado por las instituciones acreditadas oficialmente para la formación musical (29).

\section{Cierre.}

La discusión sobre qué se entiende por música y cómo concretar su práctica en territorio escolar primario sigue siendo una deuda. Hemos intentado aproximarnos al estudio de varias relaciones que se tejen entre un interés musical universal dado por la música en tanto categoría disciplinar, y contextual dado por la música como construcción cultural escolar. De alguna manera hemos visto la dificultad de discutir si estas perspectivas (desde donde pensar la música) podrían llegar a confluir en todo caso como un formato híbrido, antes que seguir segmentando las prácticas y dividiendo las aguas.

En cierto sentido la escuela reproduce los formatos de la sociedad por conservar un orden tradicionalista en relación a la música; resguarda límites entre categorías; distingue entre música como disciplina y música de sentido sociocultural contextual; aceptó alguna vez lo primero y lo sostuvo en el currículum, pero luego y al mismo tiempo volcó su interés cotidiano en lo segundo. En esta ambivalencia el perfil del docente de música es determinante para amortiguar la tensión, o por el contrario para avivarla.

La figura del docente de música es crucial y por tanto también su formación profesional en música. Las instituciones de formación musical que acreditan egresados docentes giran su proyecto en torno a la música como disciplina y no le interesa tanto lidiar su especificidad con otros campos relativamente alejados de sus referencias disciplinares, como el escolar. Vemos que en general los docentes de música han trabajado de manera insular; cada cual ha adoptado el criterio que su propia conciencia le dictó de acuerdo a su vehemencia para 
Revista de la Escuela de Ciencias de la Edducación, año 11, número 10, enero a diciembre de 2015. PÁginas 63-82. ISSN 1851-6297. ISSN EN LINEA 2362-3349. LA MÚSICA EN TERRITORIO ESCOLAR PRIMARIO: REFLEXIONES SOBRE LAS TRADICIONES PEDAGÓGICAS Y EL DEBATE SOBRE LA INTENCIÓN DE LA ESCUELA POR LA MÚSICA Y LA INTENCIÓN DE LA MÚSICA por la escuela. Carlos Peralta

posicionarse en la música como disciplina, o a su funcionalidad para con el contexto escolar.

Pero, si la impresión es que la discusión curricular para la educación musical en escuelas primarias fue deficitaria en cuanto a profundidad, carácter y frecuencia, desde aquí pensamos primero y en todo caso apreciarla como insuficientemente formal. Es decir que quizás no se hayan formalizado apropiadamente los espacios y tiempos donde darse los debates y discusiones.

Por otra parte, consideramos que la tensión en torno a resolver qué tipo de música logra entidad relevante para pertenecer a la oferta educativa escolar, tampoco ha sido yerma. En el transcurso de estos últimos años se encuentran estructurados o semi-estructurados algunos formatos musicales en territorio escolar que introducen cierta formalidad. Básicamente la referencia es hacia algunos de los proyectos de orquestas juveniles, escuelas orquestas, etc. Auspiciosamente vienen apareciendo proyectos musicales que de a poco se van institucionalizando de manera parcial pero progresiva, y que residen en componer un renovado nexo articulatorio entre el mundo de la cultura musical escolar y el mundo del lenguaje musical en tanto disciplina. Claro que es un vislumbre, pero en los casos mejor observados (30) convence en que no se alejan las producciones musicales escolares del campo disciplinar de la música, pero tampoco intenta este campo imponer hegemónicamente una autonomía estoica e indiferente a la realidad contextual de la escuela. Es un horizonte prometedor que de cierta manera deja atrás o supera las dicotomías binarias, y en el sentido que lo piensa García Canclini (op. Cít.) promueve oblicuidades y un renovado tejido cultural como resultado de variados procesos de hibridación. En algunos de los proyectos de escuelas-orquestas estas transformaciones de perspectivas están entonadas con renovar y re-significar prescripciones de tipo curricular, y así nutren y reverdecen el campo del currículum. De esta manera es posible entender la tensión como cinética para la innovación.

\section{Notas Bibliográficas}

(1) Se hará alusión más adelante.

(2) "Cotidianeidad" en términos de Cullen, C. (1996)

(3) Nos referimos a instituciones de formación musical con acreditación estatal: conservatorios, escuelas de música, facultades dependientes de universidades, institutos de nivel terciario, etc.

(4) También a través de cómo se diseña el currículum de educación musical, pero obsérvese que a nivel escolar se hace responsable como intérprete idóneo del diseño curricular al docente de música.

(5) Al respecto del canon para el caso de la música y su vuelco hacia el cuerpo orgánico de la cultura a través de las instituciones recomendamos la lectura de Omar Corrado: "Canon, hegemonía y experiencia estética: algunas reflexiones". Revista Argentina de Musicología, 2004-2005, pp.5-6 y pp.17-44. 
Revista de la Escuela de Ciencias de la Educación, año 11, número 10, enero a diciembre de 2015. PÁginas 63-82. ISSN 1851-6297. ISSN EN LINEA 2362-3349. LA MÚSICA EN TERRITORIO ESCOLAR PRIMARIO: REFLEXIONES SOBRE LAS TRADICIONES PEDAGÓGICAS Y EL DEBATE SOBRE LA INTENCIÓN DE LA ESCUELA POR LA MÚSICA Y LA INTENCIÓN DE LA MÚSICA por la escuela. Carlos Peralta

(6) Es importante aquí reflexionar hasta qué punto las institucionales acuñan la formación de sus egresados. Por tanto es fundamental observar tres indicadores puestos a darnos indicios del eje sobre el cual giran los preceptos institucionales de formación musical en las instituciones afines y ya citadas. Estos son: el peso del repertorio basado en el academicismo legado de Europa, la preminencia en el lenguaje de la normativa teórica clásica, los aspectos curriculares sustentados mayormente en unidades constitutivas de la disciplina, la temática de la mayoría de las actividades de extensión académica en torno al campo específico de la música, la menor carga horaria prevista para los aspectos pedagógicos inmediatos a la educación común, entre otros.

(7) Prácticas cuya intención persigue la formalización de asociaciones sonoras.

(8) Estudios transculturales, etnomusicológicos y musicológicos vienen debatiendo una serie de variedad al respecto de dar definición a la música. Este debate es actualmente tratado de manera local en en seminario "Antropología De La Música: Problemáticas Epistemológicas, Teóricas y Metodológicas”- FHyA, Universidad Nacional de Rosario; dictado por el Lic. Doctorando Marcelo Domenech.

(9) Cultura escolar: es amplia la bibliografía al respecto. Aquí vamos a tomar no tanto definiciones sino territorializaciones de procesos culturales, cuyo territorio en cuestión es la escuela primaria y su cotidianeidad. Entonces nos referiremos a lo que al respecto formula M. Cole $(1999 ; 2003)$ en cuanto a la construcción cultural en la relación sujetos - medio ambiente, y, Dussel (2001), Pineau (2010), Lahire (2008), entre otros, desde los procesos institucionales, políticos y socioculturales.

(10) Debe interpretarse también que los significados y perspectivas ponen en juego ciertas prácticas. Instamos a no intentar comprender lo uno sin lo otro.

(11) Tomamos básicamente para la comprensión del término lo formulado por Philip Jackson (1998).

(12) Argentina fue unos de los primeros países latinoamericanos en incluir en su propuesta educativa oficial, la educación musical en la enseñanza primaria común, en comparación con países vecinos de similar contextualización histórica en lo político-social-cultural.

(13) En este caso cabe aclarar y llamar a la reflexión que en la Provincia de Santa Fe desde el año 2007 hasta la fecha no existe diseño curricular para música en nivel primario. Al respecto se está haciendo un trabajo de investigación que indaga sobre qué preceptos curriculares los docentes basan sus planes. Algunos resultados indican que los docentes poco se basan en preceptos curriculares y otros en los anteriores ya sin vigencia.

(14) Al interior de su contexto implica no tanto dentro de las paredes del establecimiento escuela, sino en el marco de todas las relaciones que potencialmente puedan caracterizarlo identitariamente.

(15) "Es la síntesis de elementos culturales (conocimientos, valores, costumbres, creencias, hábitos) que conforman una propuesta político-educativa pensada e impulsada por distintos grupos y sectores sociales cuyos intereses son diversos 
Revista de la Escuela de Ciencias de la Edducación, año 11, número 10, enero a diciembre de 2015. PÁginas 63-82. ISSN 1851-6297. ISSN EN LIINEA 2362-3349. LA MÚSICA EN TERRITORIO ESCOLAR PRIMARIO: REFLEXIONES SOBRE LAS TRADICIONES PEDAGÓGICAS Y EL DEBATE SOBRE LA INTENCIÓN DE LA ESCUELA POR LA MÚSICA Y LA INTENCIÓN DE LA MÚSICA por la escuela. Carlos Peralta

y contradictorios, en donde algunos de éstos son dominantes y otros tienden a oponerse y resistirse a tal dominación hegemónica. Síntesis a la cual se arriba a través de diversos mecanismos de negociación, lucha e imposición social." (De Alba, 1991, p.52).

(16) En este caso recomendamos emprender una relación conceptual entre las categorías que García Canclini (2010) desarrolla y en el sentido que lo hace. A saber: definiciones crítico-analíticas sobre "lo popular", contra-posicionamientos tradicionales entre clase hegemónica y subalterna, la distinción entre el aspecto formal y el funcional para la producción musical, la oblicuidad del entramado social puesto en la escena educativa, la circulación territorializada, desterritorializada y reterritorializada de las producciones artísticas, el impacto de las teorías de la recepción de la obra musical, las estrategias para socializar y democratizar el arte, la yuxtaposición cronológica entre premodernización, modernización y posmodernización para la interpretación de los paradigmas en vigencia, entre otras.

(17) De las instituciones a las que refiere el trabajo ya citadas anteriormente, muy pocas se han dedicado al desarrollo de la música popular. Son exiguos los casos donde su presencia se haya consolidado por ejemplo dentro del currículum. En los casos más gruesos aparece dentro de algún espacio no curricular. Además y aún incluida en el currículum, el tratamiento didáctico y metodológico es inapropiado; "se intenta que la música popular se parezca en lo posible a la música académica”. Por otro lado la musicología tradicional no se interesó por la música popular sino hasta las últimas décadas del siglo pasado donde fuera recuperada por la etnomusicología y los estudios culturales sobre música. Aun así todavía no aparece como opción válida de acogida institucional. Por otra parte tradicionalmente las mismas instituciones de la cultura han segmentado y clasificado los territorios por donde circula una música y la otra. En alguna medida continúa una invisibilización de la música popular por un déficit epistemológico, se sigue sin poder resolver la aparición de una alteridad. Inclusive la música folclórica no es desarrollada desde su genealogía popular, sino desde un arbitrio político de estelas nacionalistas.

(18) Al respecto creemos importante la lectura de García Canclini (2010). Sobre todo cuando se refiere a un proyecto escolar masivo destacando que no es un proyecto de masas, sino para las masas.

(19) Vale aclarar que no se pone a juicio por sí o por no su integración a la oferta educativa pues entre otros autores, Eisner, E. (1995), justificó explayadamente la necesidad de la educación artística para un mejor desarrollo humano y social. A su vez Cassirer (1967), Gadamer (1991) y otros autores han sostenido y argumentado sobre la relación entre la capacidad de simbolizar y el arte, abriendo cauces al desarrollo de las potencialidades perceptivas-estéticas con vistas a enriquecer el descubrimiento la realidad.

(20) Tomamos de referencia las opiniones reflejadas en la Encuesta La familia opina realizada en los albores de la Ley Federal de Educación (1994) en Provincia de Buenos Aires (Argentina) 
Revista de la Escuela de Ciencias de la Educación, año 11, número 10, enero a diciembre de 2015. PÁginas 63-82. ISSN 1851-6297. ISSN EN LINEA 2362-3349. LA MÚSICA EN TERRITORIO ESCOLAR PRIMARIO: REFLEXIONES SOBRE LAS TRADICIONES PEDAGÓGICAS Y EL DEBATE SOBRE LA INTENCIÓN DE LA ESCUELA POR LA MÚSICA Y LA INTENCIÓN DE LA MÚSICA por la escuela. Carlos Peralta

(21) Tomamos como referencia algunas opiniones de egresados de institutos de formación musical de Rosario (Santa Fe, Argentina) surgidas del trabajo de campo de un avance de investigación presentado al XIX Seminario Latinoamericano de Educación Musical de FLADEM, Montevideo, en 2013 y titulado "LA EDUCACIÓN MUSICAL EN LA ESCUELA PRIMARIA COMÚN: "Tensión pedagógica entre la formación académica docente y el interés escolar sobre el universo musical. Traducir tensión en innovación"

(22) Recomendamos para reflexionar sobre la entidad de la música en el ámbito escolar, la lectura de Akoschky, J. et al. (1999). Artes y escuela. Bs. As: Ed. Paidós.

(23) Ya ha sido usado el término praxis y conviene aclarar no tanto su significado sino mejor salvar el término de un anacronismo epistemológico: no es correcto conjugar una praxis bajo la esfera paradigmática de las disciplinas, pues el marco epistemológico de las disciplinas nos remite a ciertas propiedades del pensamiento anteriores al término de praxis usado desde el materialismo histórico, tal como lo entendemos a los fines de este trabajo. Pero por ser un trabajo cualitativo, descriptivo y crítico y pudiendo contextualizarlo en la Latinoamérica actual tomamos los criterios de análisis de García Canclini (2010) para reflexionar sobre un momento de co-existencia paradigmática, de confluencia y solapamiento que consiente para los fenómenos sociales la posibilidad de encontrarlos correspondidos a distintas corrientes del pensamiento epistemológico y al mismo tiempo-espacio.

(24) Ver Bernstein (1998), Chevallard (1991), Terigi (2007)

(25) Ver Bernstein (2001).

(26) Se considera apropiada la lectura de todo el capítulo 10 de dicha publicación. Así se amplía la comprensión que se hace a la dimensión histórica sobre la cimentación del sistema educativo desde una relación importante entre formación docente y formación cultural.

(27) Se encuestó a egresados (100) de las instituciones de formación musical acreditadas: Escuela de Música de la FHyA, UNR, Instituto Provincial de Profesorado de Música “Carlos Guastavino”, Escuela Provincial de Música de Rosario; todas de la ciudad de Rosario-Santa Fe. Estos egresados en tanto potenciales docentes se han desempeñado, se desempeñan como docentes, o bien podrían hacerlo.

(28) Esto parecería obvio, pero más que obvio es obviado y se naturaliza algo que adeuda una atención pormenorizada. Considerando el caso de Santa Fe; desde el año 2007 no existe un diseño curricular para educación musical en educación primaria común, sin embargo las instituciones de formación docentes siguen formando docentes de música. Ahora si la falta de un currículum deja incierta una orientación conceptual para mancomunar qué se entiende por música, qué pertinencia conlleva para las prácticas educativas, con qué criterios pedagógicos se están formando potenciales docentes. ¿Acaso se anticipan dan respuestas a preguntas aun no formuladas? 
Revista de la Escuela de Ciencias de la Edducación, año 11, número 10, enero a diciembre de 2015. PÁginas 63-82. ISSN 1851-6297. ISSN EN LINEA 2362-3349. LA MÚSICA EN TERRITORIO ESCOLAR PRIMARIO: REFLEXIONES SOBRE LAS TRADICIONES PEDAGÓGICAS Y EL DEBATE SOBRE LA INTENCIÓN DE LA ESCUELA POR LA MÚSICA Y LA INTENCIÓN DE LA MÚSICA por la escuela. Carlos Peralta

(29) Aún hoy en los distintos sistemas educativos hay docentes en actividad que no se han titulado con la competencia debida.

(30) Entre muchos, se hace referencia a varias de las escuelas-orquesta en Argentina, destacadamente a la Orquestra Villalobos en Porto Alegre y Ginásio de Samba en Río de Janeiro (Brasil), y varias escuelas-orquestas uruguayas y venezolanas y/o orquestas y proyectos musicales juveniles.

\section{Referencias Bibliográficas}

- Aharonián, C. (2003). ¿Otredad como auto defensa o como sometimiento? En: Brecha, 12-IX-2003, \& in: Question, No 16. Caracas: X-2003.

- $\quad$ Aharonián, C. (2004). Educación, arte y música. Montevideo: Tacuabé.

- Bernstein, B. (1998) El dispositivo pedagógico. Pedagogía, control simbólico e identidad. Madrid: Morata.

- Bernstein, B. (2001). La estructura del discurso pedagógico. Clases, códigos y control (Vol. 4). Madrid: Morata.

- $\quad$ Birgin, A. y Serra, M.S. (2012). "Cultura y formación docente: viejas fórmulas y nuevas encrucijadas". En: Más allá de la capacitación. Buenos Aires: Paidós.

- $\quad$ Chevallard, Y. (1997). La transposición didáctica. Del Saber Sabio al Saber Enseñado. Buenos Aires: AIQUE.

- $\quad$ Cullen, C. (1996). Formación ética y vida cotidiana escolar. Buenos Aires: Paidós.

- De Alba, A. (1991). Currículum: crisis, mito y perspectivas. México DF: UNAM.

- Eisner, E. (1995). Educar la visión artística. Barcelona: Paidós.

- Frigerio, G. (2007). "Grülp". En: Educar (sobre) impresiones estéticas. Buenos Aires: Del Estante.

- García Canclini, N. (2010). Culturas Híbridas. Estrategias para entrar y salir de la modernidad. Buenos Aires: Paidós.

- Gardner, H. (1997). Educación artística y desarrollo humano. Buenos Aires: Paidós.

- Lahire, B. (2008) Cultura escolar, desigualdades culturales y reproducción social. En Tenti Fanfani, E. (2008). Nuevos temas en la agenda de política educativa. (1 ${ }^{\mathrm{a}} \mathrm{ed}$.). Buenos Aires: Siglo XXI.

- $\quad$ Langer, S. (1966). Los problemas del arte. Buenos Aires: Infinito.

- Pineau, P. y Di Pietro. (2008) Aseo y presentación. Un ensayo sobre la estética escolar. Buenos Aires: Latingráfica.

- $\quad$ Pineau, P; Dussel, I. y Caruso, M. (2001). La escuela como máquina de educar. Buenos Aires: Paidós.

- $\quad$ Pineau, P. (2010). “¿De qué hablamos cuando hablamos de cultura escolar? Algunos debates recientes". En AAVV. Cultura e Identidad institucional. Buenos Aires: (12)ntes.

- Puiggrós, A. (1990). Sujetos, disciplina y currículum en los orígenes del sistema educativo argentino. Buenos Aires: Editorial Galerna.

- Puiggrós, A. (2006). Qué pasó en la educación argentina: Breve historia desde la conquista hasta el presente ( $1^{\mathrm{a}}$ ed., 2 da reimp). Buenos Aires: Galerna.

- Terigi, F. (1999). "Reflexiones sobre el lugar de las artes en el currículum escolar". En: Akoschky, J. (1999) Artes y escuela. Buenos Aires: Paidós.

- Terigi, F. (2007). "Exploración de una idea". En: Baquero, R. et al (comps.2007) Las formas de lo escolar. Buenos Aires: Del Estante. 
Revista de la Escuela de Ciencias de la Educación, año 11, número 10, enero a diciembre de 2015. PÁginas 63-82. ISSN 1851-6297. ISSN EN LINEA 2362-3349. LA MÚSICA EN TERRITORIO ESCOLAR PRIMARIO: REFLEXIONES SOBRE LAS TRADICIONES PEDAGÓGICAS Y EL DEBATE SOBRE LA INTENCIÓN DE LA ESCUELA POR LA MÚSICA Y LA INTENCIÓN DE LA MÚSICA por la escuela. Carlos Peralta

- Tiramonti, G. (2008) "Mutaciones en la articulación Estado-sociedad”. En: Sociopolítica de la Educación, Capacitación para Directivos. Ministerio de Educación Ciencia y Tecnología. Argentina.

- Willems, E. (1981). El valor humano de la educación musical. Barcelona: Paidós. 